\title{
ADVOCACIONES RELIGIOSAS Y ONOMÁSTICA EN LA DIÓCESIS DE VALENCIA (SIGLO XVI)
}

\author{
M. Milagros Cárcel Ortí
}

\section{INTRODUCCIÓN}

La realización de nuestra tesis de doctorado nos llevó al estudio de los beneficios eclesiásticos en la diócesis de Valencia durante el primer tercio del siglo $\mathrm{XVI}^{1}$, tomando como base un registro de colaciones Breviarium benefitii que Joan Alamany, notario y escriba de la Curia, recopiló en 1580 , extractando los datos de los diferentes libros de colación de beneficios que se conservaban en el Archivo.

En el mismo se registran cerca de 4.000 beneficios, correspondientes a los años 1501-1538 y que constituyen el primer volumen, según se indica en el lomo de la encuadernación, lo cual nos hace suponer que continuaría otro hasta el año 1580 , fecha de la redacción de este registro.

El libro contiene tres grandes partes, encabezadas cada una de ellas por un título correspondiente a la materia que encierra:

a) Index sive tabula omnium ecclesiarum civitatis Valencie et oppidorum Valentine diocesis in presenti libro contentorum, factarum per me Joannem Alamany, notarium, Curie Vicariatus Generalis Valencie scribam, in anno $M D L V$.

Ofrece ordenados alfabéticamente los nombres de las parroquias de la ciudad y los pueblos de la diócesis, y remite a los folios donde se pueden consultar, que corresponden a los del segundo índice.

b) Index sive tabula omnium collationum beneficiorum ecclesiarum civitatis et diocesis Valentine in presenti libro contentarum, facta $a b$ anno $M D$ usque per totum annum $M D$ LIIII et ultra.

IM. M. CÁrchl OrTi, La diócesis de Valencia y sus beneficiados (1501-1538), Valencia 1980. Tesis de doctorado (mecanografiada). 
Agrupa por orden alfabético las parroquias y los pueblos de la diócesis y dentro de cada uno de ellos, también alfabéticamente, todas las advocaciones correspondientes a los beneficios, remitiendo a los folios del mismo libro donde se encuentra el asiento registrado con datos referentes a la localización del beneficio: localidad, parroquia, advocación y capilla, y datos sobre su provisión: fecha, nombre del beneficiado, nombre del fundador del beneficio, motivo del cambio de beneficiado, nombre del antecesor y nombre del presentador o patrono.

En ocasiones los folios indicados en el índice rebasan la numeración de este volumen, por lo que deducimos que habría un segundo, de características semejantes al primero y de una extensión de unos 557 folios, que en cuanto a la cronología de los beneficios registrados abarcaría desde 1539 hasta 1580 .

c) Calandaria omnium collationum ac nonnullarum institucionum et aliorum actorum ex libris collationum Curie Vicariatus Generalis Valencie, de anno $M D$ primo usque ad totum annum $M D L X X X$ inclusive, abstracta per me Joannem Alamany, notarium, dicte Curie scribam.

Esta parte, que transcribimos en su día íntegramente, tiene una extensión de 411 folios y constituyó la base de nuestro trabajo. En ella aparecen registrados los beneficios antiguos, los de nueva fundación y otros asuntos, también extractados de los libros de colación.

El interés de este registro radica en darnos resumidos los datos de otros libros de colación, algunos conservados todavía en el Archivo Metropolitano y otros irremisiblemente perdidos, no solamente por las vicisitudes sufridas por el mencionado archivo en la pasada contienda civil ${ }^{2}$, sino debido también al abandono en que se encontraba ya durante la primera mitad del siglo XVI, como nos muestra el siguiente texto:

Infrascripta calandaria anni $M D X X X$ fuerunt abstracta a libro manuali collationum annorum $M D X X X$ et $X X X I$, unico volumine existente cum liber collationum dictorum duorum annorum, qui etiam unico volumine existebat in anno $M^{\circ} D^{o} X X X X I I$ fuit per Michaelem Corella, filium quondam Vincentii Corella, tunc carceIlarii reverendissimi et illustrissimi domini Georgii ab Austria, tunc archiepiscopi Valencie, furto sublatus ab Archivo Curie Vicariatus et venditus aromatariis et specieriis et pars ipsius libri fuit reperta

2 Cf. F. MATEU y LLops «Notas sobre archivos eclesiásticos y de protocolos del Reino de Valencias, RABM LXII (1956), 703-704. 
in posse honorabilis Joannis Hieronimi Aunes, aromatarii, que quidem pars est in in dicto Archivo (fol. $301 \mathrm{r}$.).

El libro está escrito sobre papel verjurado, un tanto amarillento por la acción del tiempo, encuademado en pergamino de color natural de la misma época de su redacción, reforzadas las tapas en su interior por una hoja de papel pegada, y presentando unas medidas de $315 \times 230 \mathrm{~mm}$. La tinta es de color negro parduzca, con fuerte composición de hierro y consiguiente deterioro en algunas de las hojas, llegando a agujerearlas, sobre todo en aquéllas que llevan letras mayúsculas. Los folios presentan un tamaño de $310 \times 215 \mathrm{~mm}$, con un amplio margen a la izquierda de $60 \mathrm{~mm}$, lugar que se aprovecha para anotar la población y la invocación o notas marginales, tanto coetáneas como posteriores, que demuestran las diversas revisiones que ha sufrido el texto. Éste aparece redactado en latín y en una escritura humanística corriente, apreciándose la intervención de dos manos en su composición.

Los beneficios son fundados, por lo general, por familias pudientes. Estas fundaciones tienen dos objetivos: asegurar el culto religioso, en primer lugar, y de ahí que se funden bajo una invocación determinada. Y, en segundo lugar, la consecución de unos sufragios por la propia alma o la de los familiares y la utilización como medio de subsistencia o ayuda económica para el beneficiado, muchas veces familiar muy allegado del fundador, el cual accedía a las órdenes sagradas sin ninguna vocación haciendo de su beneficio un modus vivendi como otro cualquiera; de ahí que acumulen beneficios o constantemente soliciten el cambio a otro que les proporcione mayor renta.

En el presente trabajo, prescindiendo de la institución beneficial y su distribución y estudio a lo largo de la amplia archidiócesis valenciana, pretendemos esbozar los siguientes puntos:

- las invocaciones en los beneficios

- las invocaciones y los fundadores de beneficios

- las invocaciones y la onomástica.

\section{LAS INVOCACIONES EN LOS BENEFICIOS}

El culto de los santos conoce una especie de ciclo vital, dentro del cual encontramos su iniciación, su esplendor y su desaparición de la conciencia 
de los fieles. Es inútil pretender que cualquier santo puede ser popular en cualquier época. Los titulares de las iglesias fueron adoptados por patronos cuando su ciclo devocional estaba vivo y operante, respondiendo a unas peculiares condiciones históricas, como contactos con el extranjero, o cuando se divulgaba la noticia de su heroico martirio o de su excelsa santidad o cuando se trasladaban sus reliquias ${ }^{3}$.

$\mathrm{Si}$ a pesar del transcurso del tiempo se adoptaron los mismos santos patronos o las mismas invocaciones en las iglesias, ermitas, capillas o beneficios, ello debe responder a una continuidad de vida religiosa en aquel lugar determinado.

En nuestro caso concreto nos interesa conocer y analizar sumariamente las devociones populares durante el final de la Edad Media y comienzos de la Moderna en la archidiócesis de Valencia, a través de los datos que nos aportan los beneficios eclesiásticos. Para ello hemos creído conveniente presentar la ordenación y agrupación de dichas invocaciones siguiendo un orden jerárquico: Jesucristo, la Trinidad y la Virgen en primer lugar, seguidos de los Ángeles, san Juan Bautista, apóstoles y evangelistas, santos hispánicos, galos, romanos o italianos, orientales y otros. El número entre corchetes situado a continuación de cada uno de ellos indica la frecuencia de aparición en la fuente consultada.

\section{Invocaciones a Jesucristo}

En algunas regiones de la Península estuvo muy extendido el culto a Jesucristo, bajo la advocación del Salvador o san Salvador, que recibieron ciertas iglesias catedrales y parroquiales.

Pierre David ha puesto de relieve que en la zona situada entre el Miño y el Mondego, y generalmente en Galicia, muchos monasterios fueron consagrados al Salvador en primer lugar, aunque llevaron también el nombre de algún mártir ilustre, que figuraba entre los patronos secundarios ${ }^{4}$.

Las advocaciones que aparecen en los beneficios son muy variadas: las hay que se refieren solamente a Jesucristo [2], a quien también llaman Salvador [14] o Redentor [1], o viene indicada por Nombre de Jesús [2]. Hay otro grupo de invocaciones que aluden a diferentes pasajes de la vida del Señor, como Pasión o Imagen de la Pasión [6], Corona de Espinas [2], Jesús con la Cruz a cuestas [1], Cinco llagas [3], Descendimiento de la Cruz

${ }^{3}$ Cf. L. LOPEZ SANtos «Santos titulares en la diócesis de León», Archivos Leoneses VI (1952), p. 28.

${ }^{4}$ Cf. E. SÁz, Advocaciones religiosas en la Barcelona attomedieval (siglos $\mathrm{X}$-Xn), Barcelona 1976, p. 9. 
[2], Sepulcro [7], Resurrección [1], Aparición a la Virgen [1], Transfiguración [2] y Adoración o Tres Reyes [4].

Aparecen además invocaciones a la Cruz, cuya adoración puede considerarse como una extensión de la tributada a Jesucristo. En España la Cruz tuvo un culto esplendoroso, sólo comparable al que se le rendía en Oriente ${ }^{5}$. Este culto es de gran arraigo popular y tradicional en España, en la celebración de la llamada Cruz de Mayo, que el pueblo celebra con multitud de antiguas costumbres escasamente religiosas, que han entrado en los dominios del folclorismo ${ }^{6}$. La Vera Cruz, Crucifijo y la Exaltación de la Cruz [15] son las maneras de expresar esta advocación.

Por último, una invocación de gran tradición en la diócesis de Valencia, es la del Corpus Christi [22]. El ambiente creado como consecuencia de las herejías, así como el fervor despertado en las almas de los místicos y en el pueblo como una lógica reacción provocaron un culto al Santísimo Sacramento que fue distinto del Sacrificio Eucarístico.

El 11 de agosto de 1264 el papa Urbano IV publicó la bula Transiturus de hoc mundo, por la cual instituía la fiesta del Corpus Christi en toda la Iglesia universal. A partir de entonces, tanto en los concilios ecuménicos como en los sínodos valentinos, las directrices orientadoras de la jerarquía nos darán abundantes testimonios que configuran el culto y la doctrina sobre la Eucaristía?

\section{Invocaciones a la Trinidad}

La fiesta de la Santísima Trinidad tuvo su comienzo en el siglo VII, en territorio franco (Aniano y Tours) y fue afirmándose lentamente a partir del siglo $\mathrm{x}$, pese a la oposición de la iglesia romana que consideraba la celebración superflua. Ignoramos cuándo se introduce esta devoción en España ${ }^{8}$.

También la Trinidad goza de fervor entre el pueblo valenciano, contabilizándose quince invocaciones a la misma. Una variante la ofrece la advocación al Espíritu Santo [11].

\section{Invocaciones a la Virgen}

Sobre el culto a la Virgen en España, los testimonios más seguros empiezan en la segunda mitad del siglo VI y continúan a lo largo del VII,

${ }^{5} \mathrm{Cf}$. id. en ibid.

${ }^{6}$ Cf. López Santos, op. cit, p. 29.

7 Cf. A. Alejos Morín, La Eucaristia en el arte valenciano, t. I, Valencia 1977, p. 25.

${ }^{8}$ Cf. SÁEZ, op. cit., p. 24 
según noticia de fuentes diversas ${ }^{9}$. La tradición del fervor mariano se ve reflejada en numerosísimos patronatos de iglesias y capillas que se dedicaban a la Sma. Virgen con el escueto título de «Santa María», concretado hoy en multitud de advocaciones y referidas muchas de ellas a la Asunción.

Las invocaciones a la Virgen las encontramos expresadas de la siguiente manera: Virgen María [44], Santa María [8]; o refiriéndose a sus fiestas: Purificación [6], Anunciación [5], Encarnación [6], Virgen María de Marzo [1], Visitación [1], Asunción [9], Natividad [4], Nombre de María [1], Presentación en el Templo [1], Concepción [9], Expectación del parto [1]; o relativas a advocaciones: Virgen María de los Ángeles [2], del Anillo [1], de la Aurora [1], de Belén [1], de Castaña [1], de Esperanza [12], de las Fiebres [3], de Gracia [7], de los Inocentes [1], del Milagro [1], de Montserrat [2], de Oreto [1], de la Paz [1], del Rosario [1], de la Sabiduría [1] y de la Salud [2]; y por último aparecen también las advocaciones de la Humildad [1], los Siete Gozos [4] y la Piedad [3].

\section{Invocaciones a los Ángeles}

También son frecuentes las advocaciones a los ángeles y así encontramos al Ángel Custodio [2], a los arcángeles san Gabriel [2] y a san Miguel [57], con algunas iglesias parroquiales dedicadas a su devoción. El culto de san Miguel está testimoniado en Oriente y en Italia desde el siglo v. Durante la Edad Media alcanzó un gran desarrollo. El relato de la aparición del arcángel en el monte Gárgano, que figura en las recensiones tardías de los pasionarios, se introduciría en España en la segunda mitad del siglo $\mathrm{x}^{10}$.

Otras invocaciones son la Aparición de san Miguel [5] y san Rafael [1].

\section{Invocaciones a san Juan Bautista}

El culto a san Juan Bautista se confunde frecuentemente con el de san Juan Evangelista, lo que origina no pocos problemas. Parece que se extendió mucho por la Península durante la época visigótica". En el caso que estudiamos parece que goza de más devoción el Bautista [37] que el Evangelista. Además, en cinco ocasiones aparece mencionado este santo sin especificar a cuál de los dos se refiere.

${ }^{9}$ Cf. id., p. 10

${ }^{10}$ Cf. id. p. 13.

"Cf. íd., p. 14. 
No todos los apóstoles tuvieron culto desde los primeros siglos. Los primeros que lo recibieron fueron los santos Pedro y Pablo, Andrés y Juan. Más tardío es el culto de Santiago el Mayor y de santo Tomás. El culto de san Pedro y san Pablo, de gran popularidad en España, tiene origen romano; el de los otros apóstoles citados, es oriental ${ }^{12}$.

En nuestro caso están representados los siguientes apóstoles: san Andrés [13], san Bartolomé [27], san Felipe [8], san Juan [31], san Judas [3], san Mateo [11], san Pedro [44], Santiago [33], san Simón [3] y santo Tomás [2].

Destacan por su nutrida representación san Pedro, san Juan, Santiago y san Bartolomé, índice de un culto antiguo y popular. A todos los supera san Pedro, señal clara de secular y permanente adhesión de la iglesia hispana, concretamente valenciana, al príncipe de los apóstoles. Aparece además una invocación dedicada a la cátedra de san Pedro [4], fiesta que conmemora el día en que Pedro entró en Roma, donde había de asentar su cátedra. Encontramos también una mención a san Pedro «ad vincula», fiesta que conmemora las cadenas que lo aprisionaron.

Como similares podríamos añadir a san Bernabé [3], san Esteban [16], san Lucas [4], san Marcos [5], san Matías [3] y san Pablo [14]. La popularidad de san Esteban arranca sobre todo de la traslación de sus reliquias. El culto a san Pablo arranca de su venida a la Península con motivo de su predicación. Por dos veces aparece una invocación a la Conversión de san Pablo.

\section{Invocaciones a santos hispánicos}

Anotamos como santos hispánicos: santo Domingo de Guzmán [6], fundador de los dominicos; santa Engracia [2], mártir de Zaragoza; y santa Eulalia [2], no sabemos si se refiere a la de Barcelona o a la de Mérida. La existencia del culto de la santa barcelonesa se remonta a la primera mitad del siglo VII, época de su pasión e himno. Algunos autores se inclinan a ver en santa Eulalia de Barcelona un desdoblamiento de la de Mérida ${ }^{13}$.

Otros son: san Félix [2], mártir de Gerona muerto en la persecución de Daciano, cuyo culto es muy antiguo; san Gil [5]; san Ildefonso [6], arzobispo de Toledo; san Julián [3], obispo de Toledo; san Licerio [1], obispo de Lérida, posiblemente francés; san Lorenzo [12], mártir; san Narciso [3],

${ }^{12} \mathrm{Cf}$. id.

${ }^{13}$ Cf. id. p. 17. 
probablemente de Gerona; santa Quiteria [3], mártir; y san Ramón Nonato [1], catalán.

Tan sólo aparece una invocación a san Vicente Ferrer y a otro santo que aun no siendo valenciano goza en estas tierras de un gran fervor popular, pues padeció martirio en la ciudad de Valencia; se trata de san Vicente Mártir [8]. Es el más célebre de los mártires hispanos y el único incorporado por el rito romano a la liturgia de la iglesia universal. Desde los primeros tiempos fue conocido en los más diversos lugares de la cuenca mediterránea $^{14}$.

Invocaciones a santos no hispánicos

Entre los santos no hispánicos que tuvieron culto en la archidiócesis de Valencia encontramos los siguientes:

a) De origen romano o martirizados en Roma: san Abdón y san Senén [3], santa Águeda [3], san Calixto [1], santa Cecilia [1], santa Elena [3], san Fabián [2], santa Inés [5], santa Lucía [21], san Sebastián [7] y santa Sofía [1].

b) De origen italiano: san Ambrosio [1], obispo de Milán; san Antonino [1], dominico de Florencia; san Antonio de Padua [4], franciscano portugués que murió en Padua; san Benito [4], fundador de la orden benedictina; santa Catalina de Siena [19]; santa Clara de Asís [3]; san Constancio [1], sacristán de Ancona; san Francisco de Asís [12] (aparece otra invocación al Traslado de san Francisco); san Gregorio, papa [6]; san Nicolás [14], obispo de Mira en el siglo IV, su cuerpo fue trasladado a Bari en 1087; santo Tomás de Aquino [3]; san Urbano V [1], papa de Aviñón.

c) De origen galicano: san Amador [3], ermitaño; san Bernardo [22], fundador de Clairvaux; santa Coloma de Sens [1], mártir del siglo II; san Dionisio [2], que no tuvo culto en España con anterioridad a los siglos x y $\mathrm{XI}$, aunque la feria de san Denis era muy popular en la época merovingia ${ }^{13}$; fue el primer obispo de París, mártir; san Eloy [2], obispo de Noyon; san Ginés de Arlés [1]; san Guillermo [4], arzobispo de Bourges (también existe otro Guillermo, ermitaño, en la Toscana que murió a mitad del siglo XII); san Honorato de Amiens [10]; san Leonardo [1], ermitaño; san Luis, rey [4]; san Martín de Tours [12], su culto, iniciado por devoción popular y espontánea, se difundió por toda la España visigoda desde el siglo vi; san Saturnino de Tolosa [1], su culto es muy antiguo en España; y san Veranio [1], obispo de Vence.

${ }^{14}$ Cf. id., p. 19

15 Cf. íd., p. 22 
d) De origen oriental: san Agustín [6]; santa Ana [26]; santa Anastasia [1]; san Antonio abad [2] (hay treinta menciones más a san Antonio, sin especificar a cuál de los dos se refiere, aunque nos inclinamos a pensar que se refiera al de Padua); santa Bárbara [15]; santa Basilisa [2], mártir turca; san Blas [10], obispo de Armenia; san Clemente [1], papa; san Cosme y san Damián [5], árabes, mártires en Siria; san Cristóbal [5]; santos Inocentes [1]; santa Isabel [5], prima de la Virgen; san Jerónimo [7]; san Joaquín [3]; san Jorge [11], mártir en Palestina; san José [5]; san Lázaro [3]; san Macario [1], ermitaño de Alejandría; santa Margarita [12], mártir de Antioquía; santa María Magdalena [23]; santa María Salomé [1], madre de Santiago y san Juan; santa Marta [4]; san Onofre [5], anacoreta egipcio; santa Paula [1], mártir de Cartago; santa Tecla [3], mártir de Arabia.

A todos ellos habría que añadir santa Úrsula [3] y las Once mil vírgenes [8], mártires cristianas del siglo v martirizadas por los hunos en Colonia ${ }^{16}$.

Por último, existen una serie de invocaciones que no se pueden incluir en ninguno de los apartados anteriores y son: Almas del Purgatorio [3], Todos los Santos [10] y Octavario de todos los Santos [1].

Concluyendo este apartado podemos decir que las invocaciones más numerosas en los beneficios se refieren al culto del Santísimo Sacramento o Corpus Christi, de la Cruz y del Nombre de Jesús, ligadas al universo teológico, cristológico y trinitario; seguidas del culto mariano con invocaciones de denominación universal: Asunción, Concepción, Esperanza, etc., o de denominación local: de las Fiebres, de la Sabiduría, de Oreto, etc.; y terminando con el culto a los santos de denominación universal: san Miguel, san Pedro, san Juan, Santiago y santa Ana o de denominación local, frecuentes en ocasiones en relación con el carácter taumatúrgico de determinados cultos: san Vicente, san Cosme y san Damián, etc.

\section{LAS INVOCACIONES Y LOS FUNDADORES DE BENEFICIOS}

Las invocaciones de los beneficios son muy variadas a lo largo del tiempo, como hemos podido observar en lo que acabamos de decir, y responden a diversos motivos. Por lo general son santos o advocaciones muy conocidas por el pueblo, de gran devoción popular en otras épocas y que todavía perduran; santos titulares de las parroquias, ermitas o conventos, de cofradías y gremios, de capillas, etc.; santos a los que el pueblo se acoge en un momento de necesidad, es decir, pestes, calamidades públicas,

${ }^{16}$ Cf. para todos los santos mencionados Ph. Roumllard-P. TenlHaRd de CHardin, Diecionario de los santos de cada día, Barcelona 1965. 
sequías, tormentas, granizo, enfermedades de los animales o de las personas, etc., implorando su favor.

La fundación de un beneficio eclesiástico, acogido bajo una advocación determinada, creemos que no se hacía al azar, sino que respondía a un motivo específico: concreta inclinación por parte del fundador hacia un santo de su especial devoción, tal vez por ser el patrón de su gremio, o el santo de su nombre o de cualquier otro familiar, o el patrón de su estamento social, o de su apellido, etc. No siempre los libros de colación y las visitas pastorales consultadas nos indican el nombre y la calidad social del fundador del beneficio, dato interesante para relacionarlo con la invocación. No obstante, intentamos exponer a continuación algunas de las causas más directas que pudieron motivar la elección de una advocación.

Nombre del fundador o de sus familiares

Es el caso más frecuente que hemos comprobado cuando contábamos con suficientes datos; el beneficio se instituye bajo la advocación del santo patrón del fundador, es decir, su nombre de pila o del de su cónyuge. Hemos registrado bastantes casos, que para una mayor claridad ofrecemos en el cuadro 1 del apéndice.

\section{Apellido del fundador}

Otras veces puede ser motivo al escoger una advocación determinada del apellido del fundador cuando éste es a su vez un nombre de persona; también es un caso frecuente, como ofrecemos en el cuadro 2 .

Tanto en el caso anterior como en éste se observa en alguna ocasión que la iglesia escogida para instituir el beneficio también coincide con el nombre o el apellido del fundador.

\section{Patrón del gremio al que pertenece el fundador}

Algunas veces es el oficio del fundador el que jugará un papel determinante a la hora de escoger el nombre del santo bajo cuya advocación se dedica el nuevo beneficio que se funda, y se piensa en el patrón de dicho oficio o profesión, como muestran estos casos (cuadro 3). 


\section{Símbolo o fervor de la nobleza}

La nobleza ha tenido siempre un patrón que le ha servido como símbolo en la representación de los tres brazos de la "Generalitat", es decir, San Jorge, patrón de los caballeros. Son varios los casos, que hemos comprobado, de coincidencia de beneficios fundados por nobles bajo esta invocación y bajo otras, como son las de san Luis, san Miguel, san Salvador y san Vicente Ferrer. Respecto a esta última, se observa que las familias de la más antigua nobleza del reino de Valencia, contagiadas del entusiasmo popular y agradecidas a la variada intervención del gran predicador, rivalizaban en públicas exteriorizaciones de cálido entusiasmo, fuertemente enraizadas en ellas, levantando altares, construyendo capillas, fundando beneficios bajo su admirable advocacion, ofreciendo homenajes de amor y reverencia hacia la persona y figura del apóstol de la paz.

La floración de estas públicas manifestaciones, documentalmente probadas, nos ofrecen un bello cuadro que viene a expresar una trayectoria que arranca desde el momento del nacimiento de Vicente Ferrer, iniciada por el conjunto de nobles que asistió al acto del bautizo en pleno siglo XIV, y continúa en marcha ascendente a través de los siglos XV al XVII ${ }^{17}$. En el cuadro 4 se puede comprobar lo que hemos expuesto.

\section{LAS INVOCACIONES Y LA ONOMÁSTICA}

El registro de colaciones de beneficios nos ha ofrecido la oportunidad de hacer una incursión en la onomástica valenciana en la época de transición a la Edad Moderna, debido a las más de 3.600 personas que nos aparecen a lo largo del texto. Estas personas son beneficiados, patronos de beneficios, fundadores, notarios y otros relacionados con los propios beneficiados; en su mayoría son varones, aunque también aparecen algunas mujeres.

Además de los datos que podría aportarnos para conocer en parte la onomástica de esa época, en la que Valencia se ve inmersa en las corrientes renacentistas y se nota el abandono paulatino de los nombres medievales por otros que corresponden a los nuevos tiempos, hemos querido plantearnos la existencia de una relación entre estos nombres de pila y los nombres de las advocaciones de beneficios, tanto los de fundación antigua $o$ anterior al siglo XVI, como los nuevos o fundados durante el primer tercio de dicho siglo, para lo cual los presentamos en el cuadro 5.

$17 \mathrm{Cf}$. V. Ferréán SALVAdor, «Fervores vicentinos en los pobles valencianos», Anales del Centro de Cultura Valenciana», XVI, 1955, p. 110. 
En todo el conjunto de los nombres analizados aparece ya un $10,3 \%$ de nombres compuestos de dos nombres, a diferencia de lo que ocurría en épocas anteriores donde lo más frecuente era la existencia de un solo nombre. Comprobamos que el fenómeno suele darse entre el estamento noble, siendo el segundo componente del nombre Jerónimo, Juan o Ramón, aparte del también compuesto Juan Bautista, cuya abundancia es considerable.

En los nombres de mujer es curioso observar la aposición de Joan como segundo elemento. Aparecen también diez nombres triples (dos de mujeres) estando integrados por Juan y Jerónimo, y un nombre cuádruple, siempre en personas pertenecientes a familias nobiliarias. El resto de las personas sigue utilizando un solo nombre para designarse.

En la lista que acabamos de presentar se aprecia claramente el mayor porcentaje alcanzado por los nombres de varón correspondientes a: Juan, Pedro, Miguel, Francisco, Jerónimo, Luis, Jaime, Antonio y Bartolomé, todos ellos típicos y abundantes en nuestras tierras en otras épocas; $y$ entre los de mujer destacan los de: Isabel, Juana, Beatriz, Catalina, Leonor, Yolanda, Ángela, Damiana, Jerónima y Úrsula. Vemos que hacen su aparición todavía incipiente los nombres de Alejandro, César, Constancio, Elena, Graciano, Julio, Octaviano, etc.

Hemos querido relacionar los nombres de pila de varón, por ser los más abundantes, con las invocaciones de beneficios, distinguiendo entre estos últimos, los de fundaciones antiguas y los nuevos; para lo cual hemos tomado los nueve nombres de varón más frecuentes y sus correspondientes porcentajes de invocaciones en los beneficios, plasmándolo todo en la gráfica 1, que en su conjunto nos ofrece los siguientes resultados: en cuanto a los nombres de persona ya hemos dicho que el de Juan es el de mayor porcentaje, con bastantes fundaciones antiguas a este santo. Es curioso destacar cómo aumenta el número de fundaciones a san Miguel y a san José, sin que conste ninguna a este santo en época medieval, a la par que también es muy bajo el número de nombres de pila. Tampoco existe ninguna fundación nueva a san Francisco, aunque abunda como nombre de persona. Los demás grupos se mantienen bastante equilibrados, aunque las invocaciones a san Luis son escasas. 


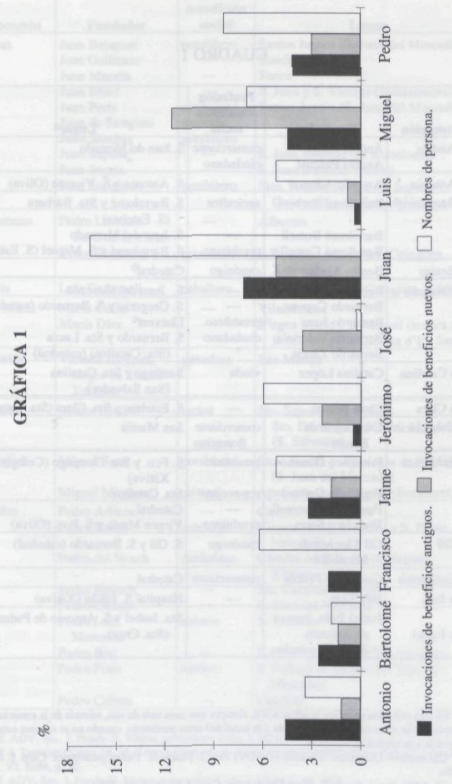




\section{APÉNDICE}

\section{CUADRO 1}

\begin{tabular}{|c|c|c|c|}
\hline Advocación & Fundador & $\begin{array}{c}\text { Profesión } \\
\text { /condición } \\
\text { social }\end{array}$ & Lugara \\
\hline San Andrés & $\begin{array}{l}\text { Andrés Ortiz } \\
\text { Andrés Pascual }\end{array}$ & $\begin{array}{l}\text { comerciante } \\
\text { ciudadano }\end{array}$ & S. Juan del Mercado \\
\hline San Antonio & Antonio Adrover & - & S. Antonio y S. Vicente (Oliva) \\
\hline San Bartolomé & $\begin{array}{l}\text { Bartolomé Barberá } \\
\text { Bartolomé Borrell } \\
\text { Bartolomé Carceller }\end{array}$ & $\begin{array}{l}\text { agricultor } \\
\text { presbitero }\end{array}$ & $\begin{array}{l}\text { S. Bartolomé y Sta. Bárbara } \\
\text { (S. Esteban) } \\
\text { S. Juan del Mercado } \\
\text { S. Bartolomé y S. Miguel (S. Esteban) }\end{array}$ \\
\hline San Benito & Benito Aladux & canónigo & Catedral $^{b}$ \\
\hline San Bernardo & $\begin{array}{l}\text { Bernardo Castellar } \\
\text { Bernardo Copons } \\
\text { Bernardo Juan } \\
\text { Bernardo Valeriola } \\
\text { Bernardo Zanón }\end{array}$ & $\begin{array}{c}\text { - } \\
\text { presbitero } \\
\text { ciudadano } \\
\text { " }\end{array}$ & $\begin{array}{l}\text { S. Juan del Mercado } \\
\text { S. Gregorio y S. Bernardo (catedral) } \\
\text { Llutxentc } \\
\text { S. Bernardo y Sta. Lucía } \\
\quad \text { (Sta. Catalina) (catedral) }\end{array}$ \\
\hline Santa Catalina & Catalina López & viuda & $\begin{array}{l}\text { Santiago y Sta. Catalina } \\
\text { (San Salvador) }\end{array}$ \\
\hline Santa Clara & Clara Fuster & - & S. Esteban y Sta. Clara (Sta. Catalina) \\
\hline San Constancio & $\begin{array}{c}\text { Constancio de } \\
\text { Barchi }\end{array}$ & $\begin{array}{r}\text { comerciante } \\
\text { florentino }\end{array}$ & San Martín \\
\hline San Francisco & $\begin{array}{l}\text { Francisco Gimeno } \\
\text { Francisco Guitard } \\
\text { Francisco Martorell } \\
\text { Francisco Serra }\end{array}$ & $\begin{array}{l}\text { presbítero } \\
\text { ropavejero } \\
\text { presbitero }\end{array}$ & $\begin{array}{l}\text { S. Fco. y Sto. Domingo (Colegiata, } \\
\text { Xativa) } \\
\text { Sta. Catalina } \\
\text { Catedral } \\
\text { Virgen María y S. Fco. (Oliva) }\end{array}$ \\
\hline San Gil & $\begin{array}{c}\text { Gil Sánchez de } \\
\text { Montalbá }\end{array}$ & canónigo & S. Gil y S. Bernardo (catedral) \\
\hline San Guillermo & Guillermo Pedrós & comerciante & Catedral \\
\hline Santa Inés & Inés Sans & - & Hospital S. Julián (Xàtiva) \\
\hline Santa Isabel & $\begin{array}{l}\text { Isabel Boix, esposa } \\
\text { de Antonio } \\
\text { Barreda, notario }\end{array}$ & & $\begin{array}{l}\text { Sta. Isabel y S. Antonio de Padua } \\
\text { (Sta. Cruz) }\end{array}$ \\
\hline
\end{tabular}

a En esta columna se indica la advocación, siempre que sean mís de una, además de la enunciada en la primera columna, el nombre de la parroquia y la localidad entre paréntesis; cuando no se expresa esta áltima. corresponde a la ciudad de Valencia.

b Cf. Archivo Diocesano Valencia (= ADV) Sec. L. Fondo II. Visitas pastorales. Carp. L. Elem. 1. fol. $165 r$.

c Cf. ADV. Sec, I. Fondo II. Visitas pastorales, Carp. I. Elem. 3, fol. $275 \mathrm{r}$ 


\section{CUADRO 1 (Continuación)}

\begin{tabular}{|c|c|c|c|}
\hline Advocación & Fundador & $\begin{array}{c}\text { Profesión } \\
\text { /condición } \\
\text { social }\end{array}$ & Lugar \\
\hline San Juan & $\begin{array}{l}\text { Juan Balaguer } \\
\text { Juan Gallisans } \\
\text { Juan Maraña } \\
\text { Juan Pérez } \\
\text { Juan Peris } \\
\text { Juan de Sampere } \\
\text { Juan Sanchis } \\
\text { Juan Saposa } \\
\text { Juan Segria } \\
\text { Juan Soriguera }\end{array}$ & $\begin{array}{l}\text { presbitero } \\
- \\
\text { ciudadano } \\
\text { tendero } \\
\text { presbitero } \\
- \\
\text { presbítero }\end{array}$ & $\begin{array}{l}\text { Santos Juanes (S. Juan del Mercado) } \\
\text { Guadassuar } \\
\text { Sueca } \\
\text { S. Juan y S. Vicente (Vilafermosa) } \\
\text { Santos Juanes (S. Juan del Mercado) } \\
\text { " } \\
\text { S. Juan Bautista (S. Bartolomé) } \\
\text { S. Juan Bautista (Alcoi) } \\
\text { Stos. Juanes, Llagas del Señor y } \\
\text { Concepción (S. Juan del Mereado) }\end{array}$ \\
\hline San Lorenzo & $\begin{array}{l}\text { Pedro Lorenzo } \\
\text { Bertí de la Volta } \\
\text { Pedro Terrades }\end{array}$ & presbitero & $\begin{array}{l}\text { Alboraia } \\
\begin{array}{l}\text { S. Lorenzo y S. Pedro (Colegiata, } \\
\text { Xativa) }\end{array}\end{array}$ \\
\hline San Luis & Luis Carbonell & caballero & S. Jorge y S. Luis (Colegiata, Xativa) \\
\hline Virgen Maria & & - & $\begin{array}{l}\text { Vilafermosa } \\
\text { Virgen Maria y S. Miguel (ermita de } \\
\text { la Muntanyeta, Callosa d'En Sarria) }\end{array}$ \\
\hline San Martín & $\begin{array}{l}\text { Vicenta Jiménez, } \\
\text { mujer de Martín } \\
\text { Jiménez }\end{array}$ & panadera & San Martín \\
\hline San Mateo & Mateo Bordell & rector & $\begin{array}{l}\text { Sto. Sepulcro, S. Mateo, } \\
\text { Sto. Domingo y Sta. M. Magdalena } \\
\text { (S. Salvador) }\end{array}$ \\
\hline San Miguel & $\begin{array}{l}\text { Miguel Sora } \\
\text { Miguel Mayques }\end{array}$ & $\begin{array}{l}\text { presbitero } \\
\text { clérigo }\end{array}$ & $\begin{array}{l}\text { Stos. Juanes y Aparición de S. Miguel } \\
\text { (S. Juan del Mercado) } \\
\text { Aparición de S. Miguel (Bocairent) }\end{array}$ \\
\hline San Pedro & $\begin{array}{l}\text { Pedro Arbeca } \\
\text { Pedro Badia } \\
\text { Pedro del Bosch } \\
\text { Pedro Enyech } \\
\text { Pedro Gençor } \\
\text { Pedro Luis } \\
\quad \text { Mercader } \\
\text { Pedro Bou } \\
\text { Pedro Prats } \\
\text { Pedro Cabata }\end{array}$ & $\begin{array}{l}\text { canónigo } \\
\text { ciudadano } \\
\overline{-} \\
\text { notario } \\
\text { tendero } \\
-\end{array}$ & $\begin{array}{l}\text { Castelló de la Ribera } \\
\text { Virgen Maria, S. Pedro y S. Pablo } \\
\quad \text { (catedral) } \\
\text { Cátedra de S. Pedro (Colegiata, } \\
\quad \text { Xàtiva) } \\
\text { Sta. Catalina (Alzira)e } \\
\text { S. Juan del Mercado } \\
\text { S. Esteban } \\
\text { S. Pedro y S. Pablo (Sta. Catalina) } \\
\text { S. Pedro y S. Onofre (S. Juan del } \\
\text { Mercado) } \\
\text { Catedralf }\end{array}$ \\
\hline
\end{tabular}

d Cf. ADV. Sec. I. Fondo II. Visitas pastonales. Carp. I. Elem. 3, fol. 310r.

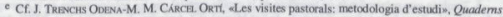
de Sueca, VI, 1984, p, 22.

f Cf. ADV. Sec. I. Fondo II. Visitas pastonailes. Carp. I. Elem. 1, fol. $187 \mathrm{r}$. 


\section{CUADRO 1 (Continuación)}

\begin{tabular}{|c|c|c|c|}
\hline Advocación & Fundador & $\begin{array}{c}\text { Profesíón/ } \\
\text { condición } \\
\text { social }\end{array}$ & Lugar \\
\hline Santiago & $\begin{array}{l}\text { Jaime I } \\
\text { Jaime Guarner } \\
\text { Jaime Miralles } \\
\text { Jaime Perelló }\end{array}$ & $\begin{array}{l}\text { Rey } \\
\text { tendero } \\
\text { estudiante }\end{array}$ & $\begin{array}{l}\text { Catedralg } \\
\text { Sta. Catalina (Alzira) } \\
\text { Cullera } \\
\text { Virgen Maria y Santiago (Denia) }\end{array}$ \\
\hline San Salvador & Salvador Joan & presbítero & S. Juan del Mercado \\
\hline
\end{tabular}

\section{CUADRO 2}

\begin{tabular}{|c|c|c|c|}
\hline Advocación & Fundador & $\begin{array}{l}\text { Profesión / } \\
\text { condición } \\
\text { social }\end{array}$ & Lugar \\
\hline Santa Bárhara & Bartolomé Barberá & agricultor & San Esteban \\
\hline San Bartolomé & $\begin{array}{l}\text { Berenguer } \\
\text { Bertomeu }\end{array}$ & ciudadano & Sta. María (Alzira) \\
\hline San Esteban & $\begin{array}{l}\text { Bartolomé Esteve } \\
\text { Juan Esteban }\end{array}$ & comerciante & $\begin{array}{l}\text { San Esteban } \\
\text { Santa Cruz }\end{array}$ \\
\hline San Juan & Poncio de San Juan & - & Santiago y S. Juan Bta. (Pego) \\
\hline San Lorenzo & Juan Llorens & - & Vilafermosa \\
\hline San Marcos & Jaime March & caballero & Catedral ${ }^{\mathrm{h}}$ \\
\hline San Pedro & Juan de Sampere & tendero & $\begin{array}{l}\text { Stos. Juanes y S. Pedro (S. Juan del } \\
\text { Mercado) }\end{array}$ \\
\hline San Vicente & $\begin{array}{l}\text { Bernardo de } \\
\text { San Vicente }\end{array}$ & canónigo & S. Vicente Mártir (catedral) \\
\hline
\end{tabular}

\section{CUADRO 3}

\begin{tabular}{|l|l|l|l|}
\hline \multicolumn{1}{|c|}{ Advocación } & \multicolumn{1}{c|}{ Fundador } & \multicolumn{1}{c|}{ Profesión } & \multicolumn{1}{c|}{ Lugar } \\
\hline San Eloy & Fernando de Tapia & platero & Sta. Catalina \\
\hline San Miguel Arcángel & Pedro Navarro & pelaire & Santa Cruzj \\
\hline Sma. Trinidad & Álvaro Rodríguez & pelaire & San Nicolásk \\
\hline
\end{tabular}

g Cf. J. Sanches Stvera, La Catedral de Valencia. Guía histórica y arística, Valencia 1909, p. 318.

h Cf. ADV Sec. I. Fondo II. Visitas pastorales. Carp. 1, Elem. 1, fol. 189v.

Este platero funda un beneficio al patrono de su gremio en la parroquia de Santa Catalina, en cuya demarcación pamoqual estaba situada la calle de la Argentería, donde seguramente tenía su taller ( $\mathrm{c}$. R. Garcia Carce, «Notas sobre población y urbanismo en la Valencia del siglo XVls, Saitabi, XXV, 1975, p. 141 .

I Este pelaire funda un beneficio bajo esta invecación. pues la cofradía a la que pertenecía se llamaba de la Sma. Trinidad y de San Miguel.

k También este pelaire funda un beneficio en la capilla gremial que los pefaires tenfan en la parroquia de San Nicolís, llamada de la Sma. Trinidad y de San Miguel. (CF. A péndice documental, item XVIII, donde se recoge integramente el testamento de Álvaro Rodriguer). 


\section{CUADRO 4}

\begin{tabular}{|c|c|c|c|}
\hline Advocación & Fundador & $\begin{array}{c}\text { Condición } \\
\text { social }\end{array}$ & Lugar \\
\hline San Jorge & $\begin{array}{l}\text { Guillermo Crespí } \\
\text { Luis Carbonell } \\
\text { Guillermo de Vich } \\
\text { Juan de Bonastre } \\
\text { Francisca de Ripoll, } \\
\text { mujer de Pedro } \\
\text { Sánchez, caballero }\end{array}$ & $\begin{array}{l}\text { ciudadano } \\
\text { caballero } \\
\text { " } \\
\text { " }\end{array}$ & $\begin{array}{l}\text { Catedral } \\
\text { S. Francisco, } \\
\text { S. Miguel, } \\
\text { S. Jorge, S. Gil y } \\
\text { S. Mauro (S. Juan } \\
\text { del Mercado) } \\
\text { S. Juan del Mercado } \\
\text { S. Jorge y S. Luis } \\
\text { (Colegiata, Xàtiva) } \\
\text { S. Bartolomé y } \\
\text { S. Jorge (Colegiata, } \\
\text { Gandia) } \\
\text { S. Salvador, } \\
\text { S. Miguel y } \\
\text { S. Jorge (catedral) } \\
\text { S. Jorge y S. Miguel } \\
\text { (Colegiata, Xativa) }\end{array}$ \\
\hline San Vicente & $\begin{array}{l}\text { Jaime de Lensa } \\
\text { Antonio Arrover } \\
\text { Juan de Borja } \\
\text { Carlos, Luis y Jaime } \\
\text { Roca }\end{array}$ & $\begin{array}{l}\text { sen̂or de Benimámet } \\
\text { duque de Gandía } \\
\text { caballeros }\end{array}$ & $\begin{array}{l}\text { Benimámet } \\
\text { S. Antonio y } \\
\text { S. Vicente }(\text { Oliva })^{\mathrm{m}} \\
\text { Pobla del Duc } \\
\text { Colegiata }\left(\text { Xativa }^{\mathrm{n}}\right.\end{array}$ \\
\hline San Luis & $\begin{array}{l}\text { Beatriz de Borja } \\
\text { Gabriel Dionís }\end{array}$ & $\begin{array}{l}\text { noble } \\
\text { señor de Canals }\end{array}$ & $\begin{array}{c}\text { Catedral } \\
n\end{array}$ \\
\hline
\end{tabular}

1 Cf. ADV Sec. L. Fondo II. Visitas pastorales. Carp. I. Elem. 1, fol. 299v.

m $\mathrm{E}$ derecho de patronato de este beneficio es ejercido por Fnncisco de Valeriola, doncel de Oliva.

n Juan de Borja ejerce el derecho de patronato

if Estos nobles ejercen el derecho de patronato 


\section{CUADRO 5}

\begin{tabular}{|c|c|c|c|c|}
\hline 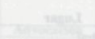 & $\begin{array}{c}\text { Nombres de } \\
\text { hombre }\end{array}$ & $\begin{array}{c}\text { Nombres de } \\
\text { mujer }\end{array}$ & $\begin{array}{c}\text { Invocaciones } \\
\text { antiguas }\end{array}$ & $\begin{array}{c}\text { Invocaciones } \\
\text { nuevas }\end{array}$ \\
\hline Abdón & 2 & & 3 & \\
\hline Águeda & 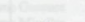 & 1 & 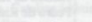 & \\
\hline Agustín & 6 & & 6 & \\
\hline Alamán & 2 & & 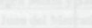 & \\
\hline Aldonza & & 5 & & \\
\hline Alejandro & 1 & & & \\
\hline Alejo & 2 & & 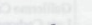 & \\
\hline Alfonso & 25 & 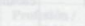 & 5 & \\
\hline Altasio & 1 & & 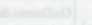 & \\
\hline Álvaro & 2 & 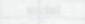 & & \\
\hline Ambrosio & 3 & & & \\
\hline Ana & 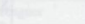 & 8 & 21 & 4 \\
\hline Andrea & 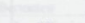 & 1 & & \\
\hline Andrés & 50 & & 11 & 2 \\
\hline Ángel & 15 & & 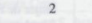 & \\
\hline Ángela & & 31 & & 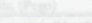 \\
\hline Antonia & 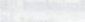 & 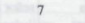 & 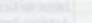 & 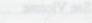 \\
\hline Antonio & 132 & $x_{2}$ & 43 & 2 \\
\hline Apolonia & 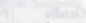 & 1 & & 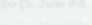 \\
\hline Asensio & 1 & 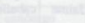 & $x^{2}$ & \\
\hline Arnaldo & 11 & 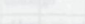 & . & \\
\hline Artaldo & 1 & 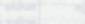 & 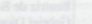 & 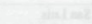 \\
\hline Ausiás & 24 & & $x^{2}=$ & \\
\hline Aymeric & 3 & & & \\
\hline Baltasar & 47 & & 1 & 3 \\
\hline Barchino & 1 & & & \\
\hline Bartolomé & 71 & & 25 & 2 \\
\hline Beatriz & & 39 & & \\
\hline Beltrán & 1 & & & \\
\hline Benita & & 3 & & \\
\hline Benito & 23 & & 4 & . \\
\hline Berengaria & & 2 & & \\
\hline Berenguer & 20 & & 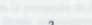 & 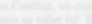 \\
\hline Bernabé & 1 & 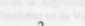 & $\sqrt{2}+x^{2}$ & 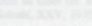 \\
\hline Bernarda & & 2 & & 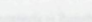 \\
\hline Bernardina & & 1 & 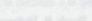 & 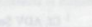 \\
\hline Bernardino & 4 & 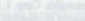 & 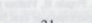 & \\
\hline Bemardo & 118 & & 21 & 1 \\
\hline Bienvenida & & 3 & 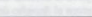 & 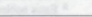 \\
\hline
\end{tabular}


CUADRO 5 (Continuación)

\begin{tabular}{|c|c|c|c|c|}
\hline 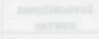 & $\begin{array}{c}\text { Nombres de } \\
\text { hombre }\end{array}$ & $\begin{array}{c}\text { Nombres de } \\
\text { mujer }\end{array}$ & $\begin{array}{l}\text { Invocaciones } \\
\text { antiguas }\end{array}$ & $\begin{array}{c}\text { Invocaciones } \\
\text { nuevas }\end{array}$ \\
\hline Blas & 3 & 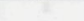 & 10 & 1 \\
\hline Blasco & 1 & & & $x^{2}$ \\
\hline Bononato & 2 & $\sqrt{2}$ & & 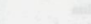 \\
\hline Bonifacio & 1 & & 1 & | \\
\hline Brígida & & 6 & & 2 \\
\hline Brunisenda & & 1 & & 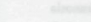 \\
\hline Buenaventura & & 1 & & 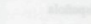 \\
\hline Calixto & 2 & & 1 & $4 x^{2}=2$ \\
\hline Camilo & 2 & 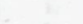 & & $x^{2}=$ \\
\hline Carlos & 10 & 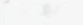 & & $x^{2}$ \\
\hline Carmona & & 1 & & ran \\
\hline Carolina & & 2 & & 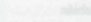 \\
\hline Carroz & 1 & & & 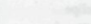 \\
\hline Castellana & & 7 & & $x^{2}$ \\
\hline Castellano & 1 & & 4 & 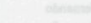 \\
\hline Catalina & & 34 & 18 & 1 \\
\hline Cocilia (Sicilia) & & 4 & 1 & y \\
\hline César & 1 & 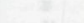 & & $x^{2}=x^{2}$ \\
\hline Cipresio & 1 & & & $x^{2}=$ \\
\hline Cipriano & 1 & & 80 & $x^{2}=$ \\
\hline Clara & & 1 & 3 & 2ne \\
\hline Clemente & 1 & & 1 & $x^{2}+2 x^{2}$ \\
\hline Cleofás & 2 & & & $\sqrt{2}=$ \\
\hline Conrado & 1 & 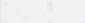 & 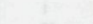 & 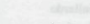 \\
\hline Constancio & 1 & & 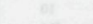 & 1 \\
\hline Constanza & 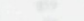 & 2 & 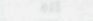 & $\sqrt{n}$ \\
\hline Corberán & 3 & & $=$ & 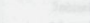 \\
\hline Cosme & 21 & 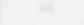 & 5 & 1 \\
\hline Cristóbal & 21 & & 5 & \\
\hline Cubella & & 1 & & \\
\hline Dalmacio & 2 & & $c^{2}$ & $\sqrt{2}+2$ \\
\hline Damián & 16 & 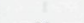 & 5 & 1 \\
\hline Damiana & & 26 & & 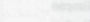 \\
\hline Daniel & 1 & 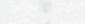 & & $\sqrt{2}$ \\
\hline Delfina & & 4 & & and \\
\hline Diego & 23 & & & 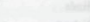 \\
\hline Dimas & 1 & & 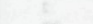 & 20. \\
\hline Dionisio & 7 & & 2 & $\sqrt{2}+x^{2}$ \\
\hline Domingo & 43 & & 5 & 1 \\
\hline
\end{tabular}


CUADRO 5 (Continuación)

\begin{tabular}{|c|c|c|c|c|}
\hline 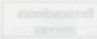 & $\begin{array}{c}\text { Nombres de } \\
\text { hombre }\end{array}$ & $\begin{array}{c}\text { Nombres de } \\
\text { mujer }\end{array}$ & $\begin{array}{c}\text { Invocaciones } \\
\text { antiguas }\end{array}$ & $\begin{array}{c}\text { Invocaciones } \\
\text { nuevas }\end{array}$ \\
\hline Donata & 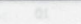 & 1 & 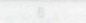 & \\
\hline Elena & & 3 & 3 & $a^{2}$ \\
\hline Elisa & & 4 & 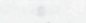 & 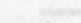 \\
\hline Eloy & 1 & & 1 & 1 \\
\hline Enrique & 10 & $x^{2}$ & & $a^{2}$ \\
\hline Eranosia & & 1 & & $x_{2}=$ \\
\hline Española & & 1 & & 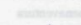 \\
\hline Esperanza & $x^{n}$ & 10 & 8 & 4 \\
\hline Esteban & 21 & & 15 & 1 \\
\hline Estefanía & 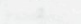 & 1 & 1 & $x^{2}$ \\
\hline Eulalia & & 1 & 1 & 1 \\
\hline Fabián & 1 & 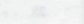 & 2 & tantin \\
\hline Felipe & 11 & & 7 & 1 \\
\hline Félix & 1 & in & 2 & $x^{2}-10$ \\
\hline Fernando & 22 & & 12 & $x^{2}=x^{2}$ \\
\hline Ferrer & 3 & 45 & & $x=$ \\
\hline Filiberto & 1 & 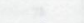 & & $x+2 x=5$ \\
\hline Florencia & & 2 & 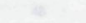 & $2=$ \\
\hline Francisca & & 15 & f & and \\
\hline Francisco & 246 & & 17 & $3 x=$ \\
\hline Gabriel & 16 & 1 & 2 & $=$ \\
\hline Galcerando & 19 & & if & $x_{1}^{2}$ \\
\hline Galea & $2=$ & 1 & $=$ & $x^{2}$ \\
\hline Gallardo & 1 & & t & $x_{12}$ \\
\hline García & 10 & & a & $y=$ \\
\hline Gaspar & 116 & ta & 1 & 3 \\
\hline Gastón & 2 & & $\sqrt{3}$ & $x=$ \\
\hline Gerardo & 12 & & 15 & $\sqrt{2}=$ \\
\hline Gil & 21 & & 4 & 1 \\
\hline Gila & & 1 & & 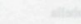 \\
\hline Gilberto & 3 & & 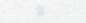 & 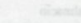 \\
\hline Gimena & & 1 & $y$ & 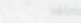 \\
\hline Gimeno & 7 & w & & 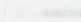 \\
\hline Ginebra & & 1 & 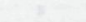 & $1=$ \\
\hline Giner & 1 & $t^{4}$ & & $a^{2}=$ \\
\hline Ginés & 13 & & 1 & 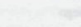 \\
\hline Gisberto & 2 & & 1 & $x^{2}$ \\
\hline Golvando & 2 & & 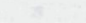 & \\
\hline Gonzalo & 8 & & + & \\
\hline
\end{tabular}


CUADRO 5 (Continuación)

\begin{tabular}{|c|c|c|c|c|}
\hline$x^{2}+x^{2}+x^{2}$ & $\begin{array}{c}\text { Nombres de } \\
\text { hombre }\end{array}$ & $\begin{array}{c}\text { Nombres de } \\
\text { mujer }\end{array}$ & $\begin{array}{c}\text { Invocaciones } \\
\text { antiguas }\end{array}$ & $\begin{array}{c}\text { Invocaciones } \\
\text { nuevas }\end{array}$ \\
\hline Gracia & $\sqrt{2}$ & 1 & 4 & 3 \\
\hline Graciano & 6 & & $21=$ & \\
\hline Graida & & 1 & & $x^{2}$ \\
\hline Gregorio & 2 & & 5 & 1 \\
\hline Guillermo & 91 & & 4 & $x^{2}$ \\
\hline Guillermona & & 2 & & 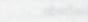 \\
\hline Hareia & & 1 & & 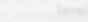 \\
\hline Herminio & 1 & & & $x_{x}$ \\
\hline Hipólita & & 1 & & $y=2$ \\
\hline Honorata & & 1 & & \\
\hline Honorato & 24 & & 8 & 2 \\
\hline Inés & & 5 & 4 & san \\
\hline Iñigo & 1 & 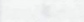 & & $x^{2}$ \\
\hline Isabel & $x^{2}$ & 87 & 2 & 3 \\
\hline Jacoba & 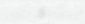 & 2 & 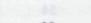 & $y^{2}=$ \\
\hline Jaime & 199 & & 30 & 3 \\
\hline Jaquesio & 1 & & nat & 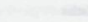 \\
\hline Jerónima & & 24 & $4=$ & 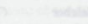 \\
\hline Jerónimo & 235 & & 4 & $x_{2}$ \\
\hline Joanot & 1 & & $=$ & 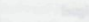 \\
\hline Jofré & 4 & & 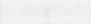 & 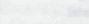 \\
\hline Jorge & 5 & & 11 & $x^{2}$ \\
\hline José & 7 & & 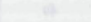 & 6 \\
\hline Josefa & & 1 & & $x^{2}$ \\
\hline Josué & 1 & & $\sqrt{1}$ & 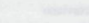 \\
\hline Juan & 659 & & 5 & \\
\hline Juan Bautista & 27 & & 32 & 5 \\
\hline Juana & 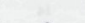 & 64 & 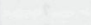 & \\
\hline Julio & 2 & & 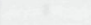 & 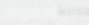 \\
\hline Justo & 1 & & & 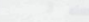 \\
\hline Lancelote & 3 & & 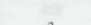 & \\
\hline Lázaro & 1 & & 3 & 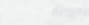 \\
\hline Leonardo & 2 & & 1 & 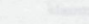 \\
\hline Leonor & & 33 & & $x_{2}$ \\
\hline Leticia & & 1 & & $x^{2}$ \\
\hline Licerio & 1 & & 1 & 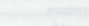 \\
\hline Lope & 3 & & 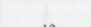 & \\
\hline Lorenzo & 21 & & 12 & tan \\
\hline Lucas & 7 & 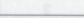 & 1 & + \\
\hline
\end{tabular}


CUADRO 5 (Continuación)

\begin{tabular}{|c|c|c|c|c|}
\hline$x^{2}+x^{2}+x^{2}$ & $\begin{array}{c}\text { Nombres de } \\
\text { hombre }\end{array}$ & $\begin{array}{c}\text { Nombres de } \\
\text { nuujer }\end{array}$ & $\begin{array}{c}\text { Invocaciones } \\
\text { antiguas }\end{array}$ & $\begin{array}{c}\text { Invocaciones } \\
\text { nuevas }\end{array}$ \\
\hline Lucía & 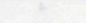 & 2 & 20 & $y^{2}$ \\
\hline Luis & 210 & & 3 & 1 \\
\hline Luisa & & 5 & & $x^{2}$ \\
\hline Magdalena & 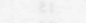 & 11 & 23 & 1 \\
\hline Maimón & 1 & & 10 & $x^{2}$ \\
\hline Manfredo & 1 & $=$ & & $y^{2}+x^{2}$ \\
\hline Manuel & 10 & 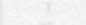 & & 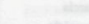 \\
\hline Marcos & 9 & & 5 & $x^{2}+2$ \\
\hline Margarita & & 14 & 13 & 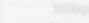 \\
\hline María & & 14 & 40 & 13 \\
\hline Mariana & 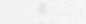 & 2 & $\sqrt{2}$ & 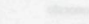 \\
\hline Marina & the & 1 & & \\
\hline Marquesa & & 3 & & 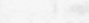 \\
\hline Marta & $\sqrt{2}$ & 1 & 4 & $x^{2}$ \\
\hline Martín & 54 & 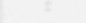 & 8 & 4 \\
\hline Mateo & 31 & & 11 & $z$ \\
\hline Matias & 4 & 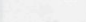 & 3 & $x^{2}$ \\
\hline Melchor & 24 & 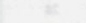 & 1 & 3 \\
\hline Menelao & 1 & 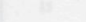 & 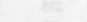 & -2 \\
\hline Miguel & 278 & & 43 & 19 \\
\hline Nadal & 2 & & $x^{2}$ & 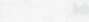 \\
\hline Narciso & 6 & & 3 & 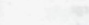 \\
\hline Nicolás & 49 & & 14 & 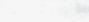 \\
\hline Nicolasa & & 1 & & $x^{2}$ \\
\hline Octaviano & 1 & & & $x^{2}$ \\
\hline Olfo & 1 & & 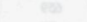 & 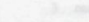 \\
\hline Onofre & 84 & & 2 & 3 \\
\hline Pablo & 7 & 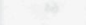 & 14 & 1 \\
\hline Pascual & 8 & & & 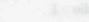 \\
\hline Paula & & 2 & 1 & 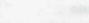 \\
\hline Pedro & 329 & & 39 & 5 \\
\hline Peregrín & 1 & & r & 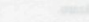 \\
\hline Petronila & & 7 & 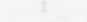 & 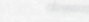 \\
\hline Pilancio & 1 & ta & & $x^{2}$ \\
\hline Poncio & 6 & & & it \\
\hline Provenza & 1 & 1 & 4 & 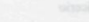 \\
\hline Querubín & 1 & & $\sqrt{1}$ & 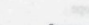 \\
\hline Rafacl & 15 & & 1 & 5 \\
\hline Rafaela & 1 & 2 & & 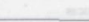 \\
\hline
\end{tabular}


CUADRO 5 (Continuación)

\begin{tabular}{|c|c|c|c|c|}
\hline . & $\begin{array}{c}\text { Nombres de } \\
\text { hombre }\end{array}$ & $\begin{array}{l}\text { Nombres de } \\
\text { mujer }\end{array}$ & $\begin{array}{c}\text { Invocaciones } \\
\text { antiguas }\end{array}$ & $\begin{array}{c}\text { Invocaciones } \\
\text { nuevas }\end{array}$ \\
\hline Ramón & 53 & & 1 & \\
\hline Rampstón & 1 & & & \\
\hline Raniero & 1 & & & \\
\hline Rigo & 1 & & 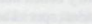 & 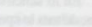 \\
\hline Rodrigo & 12 & & & 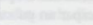 \\
\hline Roldana & & 1 & & \\
\hline Romeo & 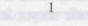 & & & \\
\hline Romia & & 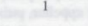 & & \\
\hline Roque & 1 & - & & 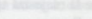 \\
\hline Sabato & 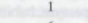 & 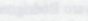 & 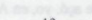 & 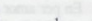 \\
\hline Salvador & 6 & 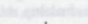 & 13 & 1 \\
\hline Samimoda & $+5=x^{2}$ & 1 & 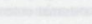 & 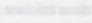 \\
\hline Sancha & 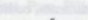 & 1 & 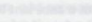 & 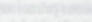 \\
\hline Sancho & 5 & 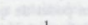 & 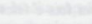 & 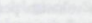 \\
\hline Sansona & 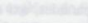 & 1 & 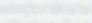 & $=2$ \\
\hline Saurina & 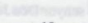 & 1 & $\sqrt{2}+2$ & 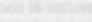 \\
\hline Sebastiain & 19 & 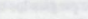 & 7 & $x^{2}=x^{2}$ \\
\hline Senén & 1 & 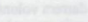 & 3 & $3+2 x^{2}=$ \\
\hline Serafin & 2 & $\sqrt{2}$ & 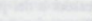 & 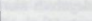 \\
\hline Sibila & $\sqrt{2}=$ & 1 & 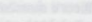 & 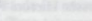 \\
\hline Silvestre & 2 & 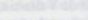 & 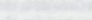 & 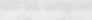 \\
\hline Simeón & 14 & 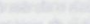 & and & 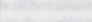 \\
\hline Simón & 2 & 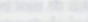 & 3 & $\sqrt{2}+x^{2}$ \\
\hline Tecla & 2 & $x^{2}=x^{2}$ & 3 & ran \\
\hline Teresa & & 1 & 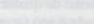 & $x^{2}$ \\
\hline Tobias & 1 & 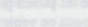 & 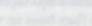 & 4 \\
\hline Tomís & 34 & 1 & 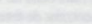 & 4 \\
\hline Tomasa & & 1 & & 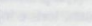 \\
\hline $\begin{array}{l}\text { Tristán } \\
\text { Úrsula }\end{array}$ & 1 & 22 & & 3 \\
\hline $\begin{array}{l}\text { Ursula } \\
\text { Valero }\end{array}$ & 1 & & & \\
\hline Vicenta & & 1 & & \\
\hline Vicente & 55 & & 7 & 1 \\
\hline Vidal & 2 & & & \\
\hline Yolanda & & 34 & & \\
\hline Yván & 1 & & & \\
\hline
\end{tabular}


1511, septiembre, 25. Valencia.

Testamento de Álvaro Rodriguez, pelaire, en el que instituye un beneficio en la iglesia de San Nicolás de Valencia, bajo la invocación de la Sma. Trinidad y San Miguel, dotado con 22 libras y 10 sueldos de renta anual.

ADV. Sec. I. Fon. III. Colación de beneficios, Carp. 15 (1518-1520), fol. 375 r. -380 r.

En lo sanctíssim y beneït nom de Jesús y de la sanqtíssima Verge Maria, mare sua, de tots los pecadors special advocada, com algú en carn posat a la mort corporal escapar no puixa, la hora de la qual és incerta, e per ço e pertany de tota persona savia pensar en aquella y en tal manera dispondre e ordenar de ses bens mentres ha spay de vida e esta ab pensa reposada, que quant nostre senyor Jesuchrist, salvador nostre, lo voldra al seu sanct regne appellar, puixa bon compte donar e retre de ço que la majestat açó manat li haurà.

En per amor de açó, yo, en Alvaro Rodrigues, perayre, habitador de la present ciutat de València, detengut de greu malaltia, de la qual tem morix e stant emperò en mon bo, sa e acostumat enteniment e memòria e ab paraula clara e manifesta, cessant primerament $\mathrm{e}$ anul-lant tots e qualsevol testaments, codicils $\mathrm{e}$ altres darreres voluntats per mi fets e fetes en poder de qualsevol notari o notaris e altres privades persones e sots expressió de qualsevol paraules, axí derogatories com altres, ara de nou invocada la misericòrdia de nostre senyor Déu Jesús Christ e de la sua mare gloriosíssima, convocats e pregats los testimonis e notari dejús scrits, fas e orden lo present meu testament e darrera voluntat mia, en la qual institueixch, fas e elegeixch marmessors e del present meu testament execudors los venerables mossèn Hieroni Pellicer e mossèn Hieroni Martí, preveres, beneficiats en la església parroquial de Santa Creu de la ciutat de València, e la dona na Andreua, molt chara e amada muller mia, absents, als quals o als dos de aquells done e otorgue licència e facultat, plen e bastant poder, tants de mos bens pendre, vendre e alienar que basten a fer e complir tot lo qua s'haura de fer e inseguix per la dita mia marmessoria, licència ni autoritat de qualsevol jutge, axí ecclesiàstich com secular en açó no esperada ni demanada e açó façen e fer puxen per llur pròpia auctoritat e sens dan algú que a ells ne a llurs bens ne vingua ne venir puixa en manera alguna.

[I] E primerament, ans de totes coses, vull, disponch e orden que tots mos bens, deutes, torts e injúries, sien pagats e paguades, satisffets e satisffetes, restituhits e restituhides aquells emperò e aquelles que legítimament se mostrarà yo ésser tengut e obligat ab cartes, testimonis o altres legítimes proves for de ànima benignament observat.

[II] En aprés recomanant la mia ànima a nostre senyor Déu, qui aquella ha creada, elegeixch sepultura al meu cors donadora en la església parrochial del gloriós Sant Nicolau de la ciutat de València, en lo vas o capella de la confraria dels perayres, hon jaen e son sepultats los confrares de la confraria appellada de la Sanctíssima Trinitat e del gloriós ar // chàngel Sent Miquel, de la qual confraria yo so confrare, prenint de mos bens distribuhidors per ànima mia e de tots fehiels defuncts cinquanta lliures moneda reals de València, de les quals vull, orden e man la mia sepultura ésser feta intrevenint-hi dotze preveres e la creu massior de la 
parroquia de Senta Catherina, ab letania, anniversari e capdany bé e complidament, segons ma condició, a coneguda dels dits meus marmessors ab que en lo dia de l'aniversari sia dita e celebrada missa major ab diacha e sotsdiacha en la dita capella de la dita confraria.

[III] E la qual dita ma sepultura vull, disponch e orden entrevingua la dita confraria dels perayres, de la qual yo so confrare, a la qual vull e man sia donada $e$ pagada la charitat acostumada, axí per ésser yo confrare com per lo venir a la mia sepultura.

[IV] Item, vull, disponch $\mathbf{e}$ orden que en la dita capella dels dits confrares e altres capelles de la dita església de Sant Nicolau sien dites e celebrades en lo dia de la mia sepultura hi dir-se poran, si no en lo dia de l'aniversari e capdany, tantes misses de requiem quantes dir se poran, en remissió de mos pecats y en suffragi de les ànimes mia e de mos pare e mare e de tots fels defuncts, per aquells prevere o preveres, frares o capellans que als dits meus marmessors ben vist los serà, donant a cascun de aquells la charitat acostumada.

[V] Item, vull, disponch e orden que en la dita capella de la dita confraria sien dites e celebrades les misses següents, ço és, tres misses en reverència de la sanctíssima Trinitat, Pare, Fill e Sanct Spirit. Item, nou misses per los nou ordens dels àngels, les quals sien dites e celebrades en la dita capella del gloriós Sent Miquel de la dita església de Sent Nicolau. Item, cinch misses de les cinch flagues sacratíssimes que monsenyor Déu Jesu Christ sofferí en l'arbre de la vera creu. Item, set misses per los set goigs que la sacratíssima Verge Maria agué de son gloriós fill.

[VI] Item, vull, disponch e orden que sien dits e celebrats per ànima mia e de tots fels defuncts, en remissió de nostres pecats, cinch trentenaris de les misses, vulgarment dites del gloriós Sent Amador, ab ses candeles e offerta, segons es acostumat, la hu dels quals dits trentenaris vull sia celebrat en la dita església de Sent Nicolau, l'altre en la dita església de // Senta Creu, l'altre en la església de Senta Catherina, l'altre en lo monestir de la Sanctíssima Verge Maria de Jesús, l'altre en lo monestir de Senta Clara de la ciutat de València, los quals sien dats e celebrats per aquells prevere o preveres, frares o capellans que los dits meus marmessors volran e ben vist los serà.

[VII] $\mathrm{E}$ hi per a fer e complir totes les dites coses, alguna cosa o quantitat hi faltarà $\mathrm{o}$ menester serà, vull, disponch $\mathbf{e}$ orden que per los dits meus marmessors sien venuts tants de mos bens fins que hi sia fet compliment.

[VIII] E hi fetes e complides les dites coses, alguna cosa o quantitat hi sobrara, vull, disponch e orden que tot alló, tant quant sia per los dits meus marmessors sia distribuhit en fer dir misses de requiem per ànima mia e de tots fels defuncts a coneguda dels dits meus marmessors.

[IX] Item, vull, disponch e orden que dels dits bens e drets meus sia esmerçat un perpetual de deu sous de renda, lo qual cascuns anys se aia de celebrar en la dita capella de la confraria dels perayres, en lo dia aprés del gloriós archàngel Sent Miquel, per los capellans e clero de la dita església de Sent Nicolau, los quals sien tenguts fer absolució general sobre lo dit vas e sepultura dels dits parayres, ab son respons com se pertany. 
$[\mathrm{X}]$ Venint en aprés a distribució e ordinació de tots los altres bens e drets meus do e leix als dits mossèn Jeroni Pellicer e a mossèn Jeroni Martí, preveres e marmessors meus, qui desús sengles gramalles e capirons de drap de dol per llurs treballs sostenidors en la dita marmessoria.

[XI] Item, vull e orden que sia donada una gramalla e capiró de dol a mon germà Ferrando Rodrigues per què s' aja vestir de negre e porte dol de la mia mort.

[XII] Item, confesse y en veritat regonech que la dita n'Andreua, molt chara e amada muller mia, ha e té en mos bens y en la dita casa mia cent cinquanta lliures de la dita moneda, ço és, quaranta lliures, les quals aquella portà e constituhí en dot al temps del seu y meu matrimoni ab cartes nupcials, rebudes per lo discret en Anthoni Julià, notari, en lo any de la Nativitat de nostre senyor Déu Jesu Christ mil quatrecents noranta $[\ldots]$ a [...] del mes de [...] e vint lliures que yo li fiu de creix o augment segons fur de València a la restant quantitat yo he rebut de bens parafernals de aquella.

[XIII] Les quals dites cent cinquanta lliures vull e man, aprés obte meu, li sien donades e pagades de mos bens e de les quals, axí dels bens parafernals com de les vint y cinch lliures de creix, puixa fer e faça a les propries voluntats no obligant lo fur del // present Regne.

[XIV] Item, do e leix a Jaume Rodrigues, fill meu, e de la dita na Andreua, muller mia, legittim e natural per part e per legíttima e per tot e qualsevol dret que aja $e$ li pertaygua en mos bens [...] set milia cinch-cents sous moneda reals de València, los quals vull e man li sien donats per la herència mia dejús scrita, en contemplació de matrimoni en temps que farà e fermarà aquell a fer de aquelles a ses pròpries exlliberes voluntats aquell carnalment $e$ ab efecte casant-se.

$[\mathrm{XV}] \mathrm{E}$ si cars serà que lo dit en Jaume Rodrigues, fill meu, no contractara de matrimoni carnal ans no-s volgués casar o del-liberava ésser de església o entrar en religió, vull, orden e man que los dits set milia cinch-cents sous sien esmerçats en un censal o censals en lochs tuts e segurs e que de la renda de aquell o aquells aja de ésser alimentat $\mathrm{e}[\ldots]$ de vida sua tant solament.

[XVI] E en cars de luició e quitament dels dits censals o censals vull e man sien tomats a resmerçar en lochs tut e segur segons dessús es dit. E d'els quals dits set milia cinch-cents sous en los dits cassos en son últim testament e darrera voluntat sua puixa dispondre e testar de cinquanta lliures a tant solament, les quals dites cinquanta lliures en lo dit cars do e leix al dit en Jaume Rodrigues, fill meu, per part e per legítima e per tot altre qualsevol dret que li pertaygua o pertànyer puixa en mos bens, com ma intenció e voluntat sia que de falliment lo dit mon fill, com dit he, sens contractar de matrimoni, entrant en religió a les ajen de tomar los dits set milia e cinch-cents sous restants als honorables en Ferrando Rodrigues, jermà meu, habitador de la present ciutat de València e a na Maria Rodrigues, jermana mia, vidua, habitadriu en lo loch de Agreda, del regne de Castella, six vius seran, per eguals parts entre aquells fahedores, si no a l' altre de aquells que en lo temps de sa mort sobreviurà.

[XVII] E si algú de aquells en lo temps de la mort del dit Jaume Rodrigues viu no serà, vull, orden e man que de los dits sis milia cinch-cents sous sien e ajen de venir a mos parents més propinchs e acostats en grau de parentela, entre aquells 
partidors per eguals parts, axí de part de pare com de mare, preferint tots temps los de part de pare, els quals, en lo dit cars, done, leixe e legue a aquells los cinch milia cinch-cents sous.

[XVIII] Tots los altres bens meus, axí mobles fehents com semovents, deutes, drets e accions a mi pertanyents o pertànyer podents e devents, luny o prop per qualsevol títol e causa, manera e rahó, ara o en lo esdevenidor do e leix a la dita na An // dreua, muller mia molt chara e aquella hereua mia propria e universal e encara general fas e institueix per dret de institució sots tal emperò vincle e condició que, mort aquella quant que quant en tal cars vull, orden e man que tots los dits bens e drets meus e de la mia herència vinguen e sien del dit Jaume Rodrigues, fill meu e a aquell en lo dit cars hereu meu propri e universal, fas e institueix e a la dita na Andreua, muller mia mare de aquell, quant que quant sens fills legittims e naturals e de legítim matrimoni e carnal nats e procreats, lo que Déu no vulla, en tal cars vull, disponch, orden $\mathrm{e}$ man que dels dits bens meus se faça $\mathrm{e}$ institueixca, axí com jo de present en lo dit cars fas e institueix un benefici en la dita capella de la sanctíssima Trinitat, hon lo meu cors jaura, sots les dites invocacions de la sanctíssima Trinitat y de Sent Miquel archàngel, lo qual benefici vull sia dotat axi como yo de present dote de vint y dos liures deu sous de renda annual, ço és, vint liures per la vida e sustentació del beneficiat del dit benefici e dels successors en aquell y dues lliures deu sous per la celebració de un anniversari perpetual, lo qual fas e institueix en la dita església cascun any y perpetualment, celebrador per los preveres de aquella e suffragi de la mia ànima e de mon pare, mare e altres parents meus defunts, los quals dits cinquanta sous, sien pagadors annualment per lo beneficiat del dit benefici de la dita renda del dit benefici e lo qual sia celebrat en lo huyten dia ans de la festa de Tots Sants, ab missa cantada ab diacha e sotsdiacha e que en lo dit dia no-s puixa celebrar altre anniversari. E en la fi de aquella se faça absolució general anant a fer absolució al vas e o fossa hon jo jauré. E lo qual beneficiat del dit benefici e los successors en aquella sia tengut e obligat entrevenir en la dita sglésia en totes les hores, axi diumes com nocturnes, e dir e celebrar tres misses cascuna sermmana.

[XIX] Les quals vint y dues liures deu sous de la dotació del dit benefici vull, orden e man que per los majorals de la dita loable confraria de la Sanctisima Trinitat y del gloriòs archàngel Sent Miquel, que en lo dit cars majorals se trobaran, sien presos tants de mos bens e aquells sens solempnitat alguna e sens auctoritat e decret de official ni jutge algú, ecclesiàstich ni secular, per sa sola propria auctoritat puixa vendre y alienar $\mathrm{e}$ los preus rebre, confessant haver agut e rebut aquells fahents $y$ fermants // vendes $y$ alienacions $y$ àpoques dels dits preus ab totes les clàusules necessàries. E los preus que de aquells procehiran sien per aquells esmerçats a censal o censals en lochs tuts e segurs, a rahó de quinze milia lo miller. E axí, esmerçats per aquells, sien donats e consignats al dit benefici anniversari y perpetual, procehint emperò licència de la majestat del senyor rey e pagat en altra manera.

$[\mathrm{XX}] \mathrm{E}$ do e leix lo jus patronat de dit benefici als dits majorals e clavari de la dita loable confraria de la Sanctísima Trinitat, appellada dels perayres e als successors en los dits offici de majorals e clavari. En axí que tota hora e quant lo dit benefici sia consignat e decretat per lo reverent official y vicari general sia presentat 
en lo dit benefici lo dit benerable mossèn Hieroni Pellicer, prevere, si en lo dit cars viu serà, e si viu no serà e o aprés obit de aquell dit mossèn Jeroni Pellicer, vull sia presentat en lo dit benefici lo venerable mossèn Hieroni Martí, prevere e marmessor qui dessús. E si serà cars que dits marmessors contrats no seran, vull, disponch e orden que los dits majorals e clavari sien tenguts de presentar en dit cars, aprés òbit dels dits mossèn Jeroni Pellicer e mossèn Jeroni Martí, preveres, marmessors meus, qui dessús en lo dit benefici un parent meu més propinch en grau de parentela de part de pare, si ni aurà e si no, als pus propinchs parents de part de mare, en axí que tots temps preceixquen los parents de part de pare, lo qui més propinchs serà en grau de parentela a aquells.

[XXI] E no havent-hi ni trobant-se parents meus axí de part de pare com de mare, en tal cars vull, orden e man que per los dits majorals e clavari sia presentat en lo dit benefici tostemps que vagara los parents de la dita na Andreua, muller mia, pus propinchs en grau de parentela de aquella, axí de part de pare com de mare, precehint emperò tostemps los parents pus propinchs a aquella de part de pare. E si parents alguns no y haurà ni-s trobaren de part de pare ni de mare de la dita muller mia, en tal cars vull e man que per los dits majorals e clavari concordantment ajen de presentar en dit benefici tostemps que vagarà un fill // de confrare de la dita confraria, que sia prevere, bo, honest y de bona vida, que no tinga benifet algú e que més necessitat tendrà. $\mathrm{E}$ aprés segueixca tostemps que lo dit benefici vagarà $\mathrm{e}$ fet $\mathrm{e}$ complit ab tot efecte lo dit benefici fet dotat e consignat aquella segons dessús es dispost e ordenat per mi.

[XXII] Tot lo restant dels dits bens e drets meus e de la dita ma herència done $e$ deixe als dessús dits en Ferrando Rodrigues, jermà meu y a la dita na Maria Rodrigues, jermana mia, qui dessús si vius seran entre aquells, per eguals parts partidors. E si algú de aquells serà mort, en lo loch de aquell succeheixquen los fills de aquell, hu o molts, tants e com en lo dit cars vents se trobaren, per eguals parts entre aquells fahedora de la mitat dels bens de la dita mia herència. E si fills no y haurà, que sien entregament de aquell dels dits jermans meus que sobreviurà en lo dit cars. Esi aquell no viurà, en tot cars als fills de aquell si ni haurà hu o molts, tants com seran per eguals parts entre aquells fahedora.

[XXIII] E si advenint lo dit cars los dits jermà e jermana mia ni fills ni filles de aquells no y haura, en tal cars vull, orden e man que los dits bens meus vinguen $e$ sien dels pus propinchs parents meus, axi de part de pare com de part de mare, que en lo dit cars més propinchs en grau de parentela se trobaran. E-n axí que los pus propinchs a mi en grau de parentela, de part de pare si ni haurà, ajen a succehir en la dita mia heretat y bens de aquella. E si no, los de part de mare, precehint tostemps los parents de part de pare e aquells en dit cars hereus meus fas e institueix a fer de aquells a ses pròpries e líberes voluntats. E si en lo dit temps e advenint los dits casos no seran atrobats ninguns de la mia parentela, axí de pare com de mare, en tal cars vull, disponch, man e orden que tots los bens e drets meus que restaran de la mia herència sien venuts per los majorals e clavari de la dita confraria dels perayres qui lavors seran, e los preus de aquells sien esmerçats e hu o molts censals o censals en lochs tuts e segurs. Als quals dits majorals done e atorgue ple e bastant poder per 
a fer les coses dejús scrites per llur propria auctoritat sens licència de ningun jutge, axí ecclesiàstich com secular, e si e segons dejús // es estat dit per mi e ordenat.

[XXIV] Dels quals dits censals e renda de aquells disponch e man sien instituhits hu o molts beneficis simples per los dits majorals, los quals ara per lavors per ara institueixch e vull ésser instituhits, donant e assignant e dotant a cascú de aquells, precehint emperò licència de la majestat del rey nostre senyor e pagar a sa majestat lo dret de amortizació en los dits beneficis a ell pertanyent e no en altra manera vint y dos lliures deu sous de renda, ço és, vint lliures per a la sustentació de cascú dels dits beneficiat o beneficiat de aquell o aquells dits beneficis e cinquanta sous per la celebració de un anniversari perpetual, lo qual e los quals fas e institueixch en la dita església cascun any perpetualment celebrador per los preveres de aquella en suffragi de la mia ànima e de mos pare, mare e tots altres fels defuncts. E los quals dits cinquanta sous sien pagats per los beneficiat o beneficiats del dit benefici o beneficis annualment de la dessús dita renda de cascún dels dits benefici o beneficis. E lo qual e los quals vull e man sien celebrats en la huytava ans de la festa de Tots Sants, ab missa cantada ab diacha e sotsdiacha e en la forma e manera que he dit e ordenat dessús en lo benefici e perpetual dessús especificat. E los quals dits beneficiat o beneficiats ajen e sien tenguts entrevenir en totes les hores, axí nocturnes com dihurnes, que dien e celebren en la dita esglesia e sien tenguts dir e celebrar tres misses cascuna semmana en la dita capella e o altars de la Sanctíssima Trinitat e de Sent Miquel archàngel.

[XXV] Dels quals dits benefici o beneficis vull e man sien patrons los majorals e clavari de la dita confraria qui lavors seran e los qui aprés de aquells seran e succehiran en lo dit offici, donat-los ara per lavors lo jus patronat o patronats de aquells dits benefici o beneficis. En axi que tota hora e quant lo dit benefici o beneficis serà decretat per lo reverent official o vicari general sia presentat en aquell dit benefici si viu serà lo dit venerable mossèn Hieroni Martí si viu serà y si no serà col-locat en lo benefici per mi de super instituhït. E si eren dos beneficis o més seran sien presentat o presentats hu o dos fills o fills de alguns del dit offici de perayres confrares de la dita confraria ab que lo dit presentat sia prevere e de bona vida e no tinga altre benefici, preferint totstemps en tal cars los parents, axí de part de pare com de mare meus, com de part de pare o de mare de la dita na Andreua, muller mia, los quals ara per llavors vull $\mathbf{e}$ orden sien preferits en lo presentar a tots los altres fills dels confrares de la dita confraria dels dits perayres si e segons dessús he dispost e ordenat.

[XXVI] Derrerament do e leix en tudriu e curadriu de la persona e bens del dit en Jaume Rodrigues, fill meu, la dita na Andreua, molt chara e amada muller mia e mare de aquell, la qual pregue per amor de Déu vulla regir e administrar la persona e bens de aquell, segons de bona mare se pertany e yo della mort confie.

Aquest és lo meu últim e darrer testament, última e darrera voluntat mia, lo qual e la qual vull que valgua per dret de testament, e si no valrà per dret de testament vull que valgua per dret de codicil. E si no valia per dret de codicil vull que valgua per dret de testament nuncupatiu. E si no valia per dret de testament nuncupatiu vull que valgua per tots aquells drets, furs, leys, consuetuts e rahó natural scrita que mils valer puixa e dega. 
Lo qual fonch fet en la ciutat de València a vint y cinch dies del mes de setembre de l'any de la Nativitat del nostre Senyor Déu Jesu Christ mil cinch-cents onze.

Se (signo) nyal de mi Alvaro Rodrigues, testador, qui dessús qui lo present meu testament fas, lee e atorgue e ferme e vull ésser portat a deguda execució segons en aquell es ordenat.

Presents foren per testimonis e per lo dit testador fets convocar e pregats que fossen testimonis a la confecció del dessús dit testament los honorables En Jaume Roqua, En Berthomeu Sabastì e En Gabriel de Xoaria, perayres, habitadors de la ciutat de València, los quals interrogats si coneixien lo dit testador tots concordantment dixeren que si. E yo en Miquel Martí, notari dejús scrit, lo conech molt bé.

Sig (signo notarial) num mei Michaelis Marti, notarii publici civitatis et regni Valencie, qui predictis interfuit eaque per alium scribi feci // et clausi loco die et anno precontentis, cum rasis et rescriptis in lineis videlicet quarta decima ubi rescribitur in fine donacionis capelles, decima octava ubi rescribitur trentenaris et sexagesima quinta ubi rescribitur rey nostre et cum suppraponitis in lineis videlicet vigesima octava ubi suppraponitur Rodrigues et trigesima ubi suppraponitur en temps que farà e fermarà aquell, trigesima secunda tansolament, trigesima nona del et in eadem linea $t a l$, quinquagesima tercia ubi suppraponitur cars, septuagesima prima seran, septuagesima secunda ubi legitur si viu serà, septuagesima sexta e darrer et in secunda linea testium ubi suppraponitur Marti.

En aprés dilluns que-s contaven sis dies del mes de octubre del dessús any mil cinch cents y onze, que era lo segon dia aprés mort del dit defunct, presents, instants e requirents los dits venerables mossèn Hieroni Pellicer e mossèn Hieroni Martí, preveres, marmessors en lo dit testament scrits e la dita na Andreua, muller, e Jaume Rodrigues, fill del dit en Alvaro Rodrigues, quondam defunct e presents molts e altres parents, amichs de aquell que eren venguts en aquella hora de l'anniversari e capdany que 1 dit dia era stat celebrat per ànima de aquell en la casa hon lo dit testador vivint estava e habitava e hon finí sos darrers dies, lo dit testament per mi Miquel Marti, notari, rebedor de aquell fonch lest e publicat ab veu alta e intel-ligible, que tots ho podien ben entendre, lo qual lest e publicat en continent los dits mossèn Hieroni Pellicer e mossèn Hieroni Martí dixeren que per amor y reverència de nostre Senyor Déu y amor que tenen al dit defunct acceptaven lo carrech de la dita marmessoria e llegat de les dites gramalles a ells fets, e la dita Na Andreua, muller del dit defunct, dix que acceptava la confessió e legat que li era stat fet e feta la dita tutela e cura del dit son fill en lo dit nom acceptava lo legat fet al dit Jaume Rodrigues, son fill, axí com ell ho lexava, e la dita herència acceptava ab benefici de inventari, lo qual en continent dix que volia e entenía fer quant pus prest pogués. De les quals dites publicació // o respostas demanaven e requirien ésser-los feta carta pública, la qual per mi dit Miquel Marti, notari, los fonch rebuda los dia, mes e any dessús dits. 
Testimonis són qui foren presents a les dites coses los honorables En Hieroni Ferrer, En Anthoni Pallares e Luys Batalla, perayres, vehins e habitadors de la ciutat de València.

Sig signo notarial num mei Michaelis Marti, notari públich civitatis et regni Valencie, qui predictis interfui eaque per alium scribi feci et clausi loco, die et anno prefixis.

Jesus. Fiat definicio de supradictis quinquaginta libris iam distributis Jacobis Conill, auditor.

Fuit facta definicio huiusmodi testamenti per me Raymundum Guerau, notarium, regentemque curiam vicariatus generalis Valencie, sub die tercia decima marcii, anno millesimo quingentesimo duo decimo, prout in libro diffinitionum dicte curie latinis continetur.

Jesus. Et nos Jacobus Ramó, canonicus, vicariusque generalis et officialis Valentie, visa institucione dicti beneficii inpreinserto testamento continuata et omnibus et singulis quia juri sunt conformia ideo in dicta institucione dicti beneficii nostram interponimus auctoritatem pariter et decretum manu propria scriptum, die VII' anno a Nativitate Domini millesimo quingentesimo vigesimo. 